\title{
PREDICTION OF FLASH FLOOD SUSCEPTIBILITY USING FUZZY ANALYTICAL HIERARCHY PROCESS (FAHP) ALGORITHMS AND GIS: A STUDY CASE OF GUELMIM REGION IN SOUTHWESTERN OF MOROCCO
}

\author{
S. Talha ${ }^{1, *}$, M. Maanan ${ }^{3}$, H. Atika ${ }^{4}$, H. Rhinane ${ }^{2}$ \\ ${ }^{1}$ University Hassan II, Faculty of Sciences Ain Chock, Department of Earth Sciences, Casablanca, Morocco - h.rhinane@gmail.com / \\ talhasoukaina1@gmail.com .

\section{Commission IV}

KEY WORDS: GIS, Fuzzy Analytical Hierarchy Process, SMI, Morocco, Watershed, Flash Flood Susceptibility

\begin{abstract}
:
In recent decades, many of the countries around the world as well as the south-western Morocco (Guelmim region, Assaka watershed), was subject to flood-storm causing huge human and material damages. The current study focuses on the Prediction of flash flood susceptibility using Fuzzy Analytical Hierarchy Process (FAHP) algorithms and Geographic Information System (GIS) technical. Flash floods areas were identified based on seven flash flood conditioning factors (Soil Moisture Index (SMI), Drainage Density, Rainfall, LULC, Altitude, Slope and Soil). Using AHP the weight derived for the factors were SMI 37\% Rainfall 24.30\%, Drainage Density $15.57 \%$, LULC 9.98\% Altitude 6.39\% Slope of the river basin $4.06 \%$ and Soil type $2.70 \%$. Then, applying a fuzzy inference system to create flash flood vulnerability maps. The resulting maps were classified into three categories: low, moderate and high flash flood susceptibility; indicated that the areas at the outlet of the watershed and which are close of the main affluent wadis (Seyyad and Oum Al-Achar) were very susceptible to flooding. This study will be helping these zones to be prioritized for the conservation and managing of flash floods.
\end{abstract}

\section{INTRODUCTION}

Flash floods are considered to be the most widespread natural disaster in the world in these recent decades. Their consequences are not only environmental but also humanical and economical, as they can cause damage to urban zones and cultivated fields and even death (Hallegatte, Hourcade, and Dumas 2007; Jongman et al. 2012; Jonkman et al. 2008).

Morocco is a North-African country, has faced many flood events in several regions due to the impact of climate change (Hoegh-Guldberg and Bruno 2010), therefore The Guelmim region that is located at the south-western of Morocco was the most affected area and declared as a "disaster area" by the Moroccan government. This region was not destroyed for the first time but it has been flooded various times during the past 50 years, specifically in 1968, 1985, 1989, 2002, 2010 and 2014 (TARGA-AIDE and Zurich Insurance 2014). In addition, the increase of flash floods and their destructive results around the world need a continuous improvement on identifying and mapping of flash flood risk. In recent years, flash flood risk susceptibility researches have been realized by many countries (Abdelkareem 2017; Carpenter et al. 1999; Chen, Hill, and Urbano 2009; Curebal et al. 2016; Dawod, Mirza, and AlGhamdi 2011; Elkhrachy 2015). However, various methods have been used to identify and evaluate flash flood vulnerable areas in Morocco (Boutaleb et al. 2018; Echogdali et al. 2018; Hakdaoui et al. 2019; El Khalki et al. 2018; Tramblay et al. 2012; Werren et al. 2016). And only a few methods have been

used to evaluate flash flood susceptibility in Guelmim region. One of the first studies have used the Remote Sensing and GISScience for the Detection of Flooding-Prone Areas (TheilenWillige et al. 2015). A second study was used the Topographic Attributes, Hydrologic Indices, and GIS for the Detection of Areas Associated with Flash Floods and Erosion Caused by Rainfall Storm (Bannari et al. 2016). In addition, another study did the Synergy between SMOS-MIRAS and LandsatOLI/TIRS Data for Soil Moisture Mapping before, during, and after Flash-Flood Storm (Bannari, Rhinane, and Bahi n.d.). but all of these methods and studies are insufficient to give the most suitable result, for that reason, in this study case the fuzzy analytical hierarchy process (FAHP) algorithms was used for the first time to predict the flash flood susceptibility areas in Guelmim region. FAHP algorithms are more broadly used and it has been applied to a group of scientific domains (Environmental, Economical and Social). The above-mentioned studies contribute significantly and safely to comprising and removing the complication of the complex Problems by Combining the hierarchical algorithm with the fuzzification algorithm (Saaty 1989; Zadeh 1978). A lot of researchers have applied these algorithms to estimate the flash flood risk and detected that the FAHP help to get the most reliable results (Hategekimana et al. 2018; Motevalli and Vafakhah 2016; Papaioannou, Vasiliades, and Loukas 2015; Tazik et al. 2014; Yang, Ding, and Hou 2013). 


\section{MATERIALS AND METHODS}

\subsection{Study Area}

The Assaka watershed is located in Guelmim-Oued Noun region $\left(28^{\circ} 59^{\prime} 17^{\prime \prime} \mathrm{N}, 10^{\circ} 03^{\prime} 327^{\prime \prime} \mathrm{W}\right)$. A region that exists in southwestern Morocco (Figure 1). The Assaka River drains a large watershed on the southwest border of the Anti-Atlas and its Saharan boundaries in the Guelmim region (Schulz, Busche, and Benbouziane 2008). It has considered to be the confluence of the wadis, Seyyad and Oum Al-Achar (Ryu et al. 1997), which crosses the last folded chains of the Anti- Atlas before continuing it is flowing process into the Atlantic Ocean with an estimated area of $6500 \mathrm{~km} 2$ (Bannari et al. n.d.). In this watersheds, there is a very dangerous area that is declared as "disaster area" by Morocco government because of the serious damage it can make. It's Guelmim city, which exists at the foot of the western Anti-Atlas Mountains with high peaks that are reaching more than 2100 meter, it has an arid to the semi-arid desert climate, it's temperature range varies from

$12^{\circ} \mathrm{C}$ in winter to $49^{\circ} \mathrm{C}$ in summer and it's annually rainfall average is between 70 and 120 millimetres and their population is approximately 134030 hab (HCP 2014). finally, the useful agricultural area of Guelmim Region including 15000 ha irrigated (O.R.M.V 2019).

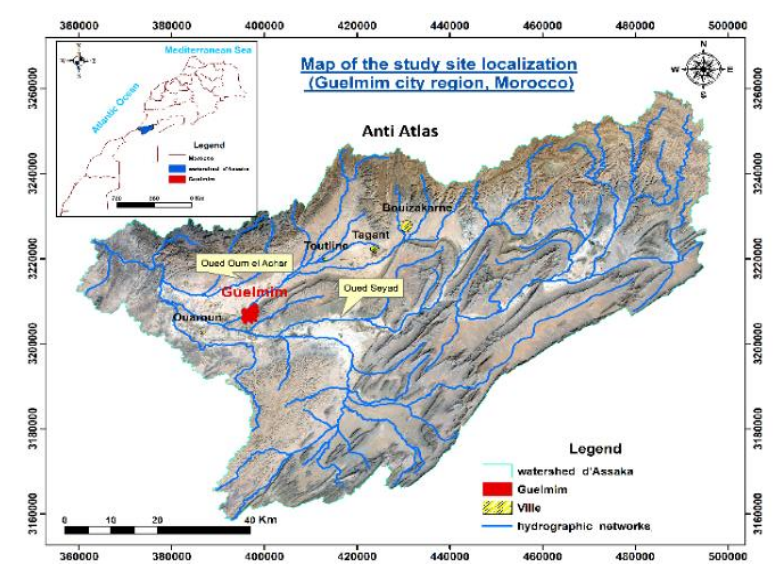

Figure 1. The Geographical Location of the Study Area

\subsection{Data Used}

The most important dates used in this study are Landsat-8 OLI Sensor and Global Digital Elevation Model (GDEM).
2.2.1 Landsat-8 OLI Sensor Data: Altitude is a natural topography representation (altimetry) of a terrestrial area. It's a very essential factor which can influence any flash flood that may exist (Wang, Yang, and Yao 2012). In general, flash flood frequency increases according to the decreasing pattern of the elevation, which means that the lower areas are more susceptible to flooding condition (Bisht et al. 2018). This Global Digital Elevation Model (GDEM) with moderate spatial resolutions of $30 \mathrm{~m}$, was Downloaded from USGS data explorer. However, in this study area, the elevation was between 17 and $1497 \mathrm{~m}$ (Figure 2).

2.2.2 Global Digital Elevation Model (GDEM): Altitude is a natural topography representation (altimetry) of a terrestrial area. It's a very essential factor which can influence any flash flood that may exist (Wang, Yang, and Yao 2012). In general, flash flood frequency increases according to the decreasing pattern of the elevation, which means that the lower areas are more susceptible to flooding condition (Bisht et al. 2018). This Global Digital Elevation Model (GDEM) with moderate spatial resolutions of $30 \mathrm{~m}$, was Downloaded from USGS data explorer. However, in this study area, the elevation was between 17 and $1497 \mathrm{~m}$ (Figure 2).

\subsection{Data Preprocessing}

Based on the information presented from prior researches (Bannari et al. n.d.; Darabi et al. 2019; Yang et al. 2018), it has enough knowledge that helps to identified and recognized the seven important flash flood susceptibility factors, that it has been used in this study case which, are soil moisture index (SMI), rainfall, drainage density, Lulc, altitude, slope, and soil.

2.3.1 Rainfall: Heavy flash floods are generally caused by high intense rainfall which means in this study, the preparation of the rainfall maps is very important to identify the flash flood susceptibility areas (Domeneghetti, Schumann, and Tarpanelli 2019), but this preparation needs a several steps one of them was to Download CRU monthly climate dataset and to convert "NETCDF" file to useable format. Another step was to separate months from bands and to generate monthly maps. After this step, we cut those maps in an organized way to form the rainfall map. Finally, the result is getting the final monthly average rainfall map with $30 \mathrm{~m}$ resolution. However, in this study, the resulting map indicated that the November rainfall was very high on average compared to the period during December, it has fallen between 24.73 and $83.83 \mathrm{~mm}$. But during December the average rainfall was between 14.78 and $25.75 \mathrm{~mm}$ (Figure 2). 
2.3.2 Drainage Density: When rainfall happens in a watershed condition, the drainage density has an impact on water circulation (Mohamed and El-Raey 2019). For that reason, the drainage density factor has an important effect on the prediction of flash flood existence possibility. Furthermore, Low drainage systems have several consequences that result in making watershed overflowing and an incessant flooding event in a certain zone. However, because of the important influence that drainage density can make. It was very useful to derive it by using the line density tool from ArcGIS software. In this study area case, the output drainage density map (Figure 2) was between 0 and $3.90 \mathrm{~km} / \mathrm{km} 2$ with $30 \mathrm{~m}$ resolution.

2.3.3 Land Use Land Cover (LULC): Lulc. At different scales is a very useful product for a resource manager, it can be drawn from a wide variety of satellite images to meet the needs of users and provide the information needed to decision makers. Land use has an important job in runoff velocity which was the main source of encouragement to use it in this study (Mashaly and Ghoneim 2018). The study zone case land use map that was created from the Landsat 8 OLI satellite image with spatial resolution $30 \mathrm{~m} \times 30 \mathrm{~m}$, and it has an indication about five important classes: Build-up, water, vegetation, agriculture and soil (Figure 2).

2.3.4 Slope: Flash Flood is directly related to slope degree and is an essential morphology characteristic (Bannari et al. 2016; Falah et al. 2019). The slope helps direct the surface runoff velocity and thus influence a flash flood susceptibility (Fenton 2019). The slope degree map was created from the GDEM raster in the ArcGIS environment. In the study area, the slope (Figure 2) was between 0 and $63.59^{\circ}$ with $30 \mathrm{~m}$ resolution.
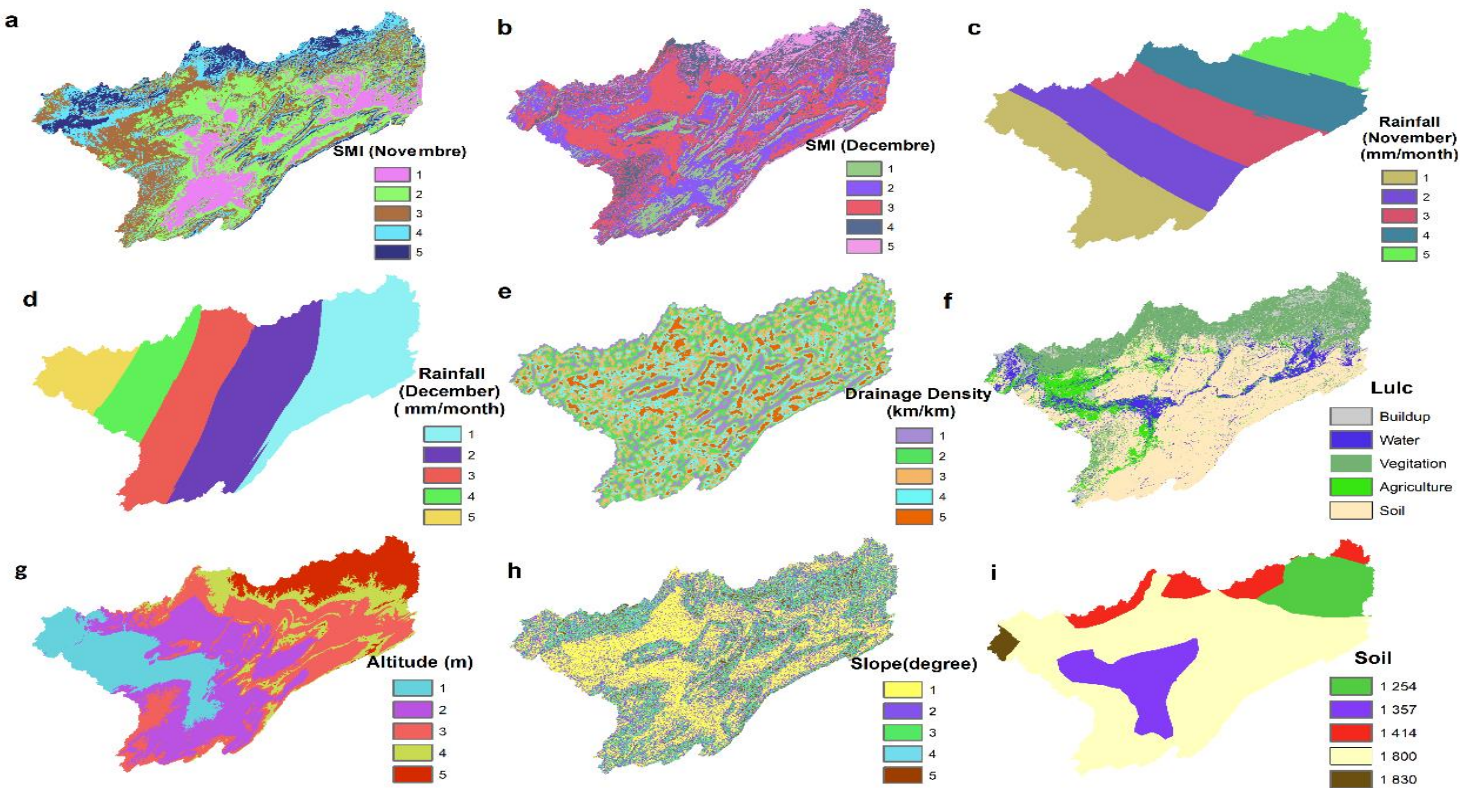

2.3.6 Soil: Soil is a porous and three-phase medium (water, air, minerals) in which micro and macro-organisms from the plant and animal world do living. The lack of water absorption by soils is one of the main causes of the genesis offloading (O'Mara et al. 2019). For that reason, the identification of the soil types in any study area is very important, but the preparation of the soil map needs to use FAO data. In this study case, the resulting map (Figure.2) indicated six categories of soil. The Calcaric Fluvisols (Jc); Chromic Luvisols (Lc); Lithosols (I); Yermosols (Y) and Haplic Yermosols (Yh). This map was Re - Projected from WGS84 to UTM.

\section{e}

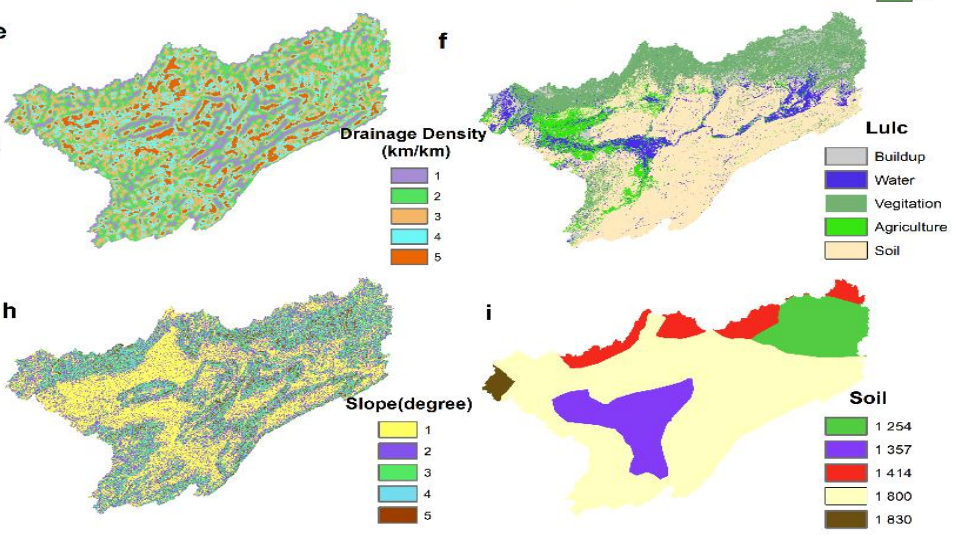

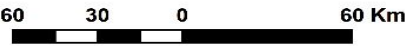

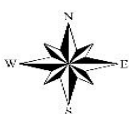

Figure 2. Flash flood conditioning factors used to create the flash flood susceptibility maps: a) SMI before flooc (November 2014), b) SMI after flood (December 2014), c) Rainfall before flood (November 2014), d) Rainfall after flooc (December 2014), e) Drainage density, f) Lulc , g) Altitude , h) Slope degree, i) Soil type. 


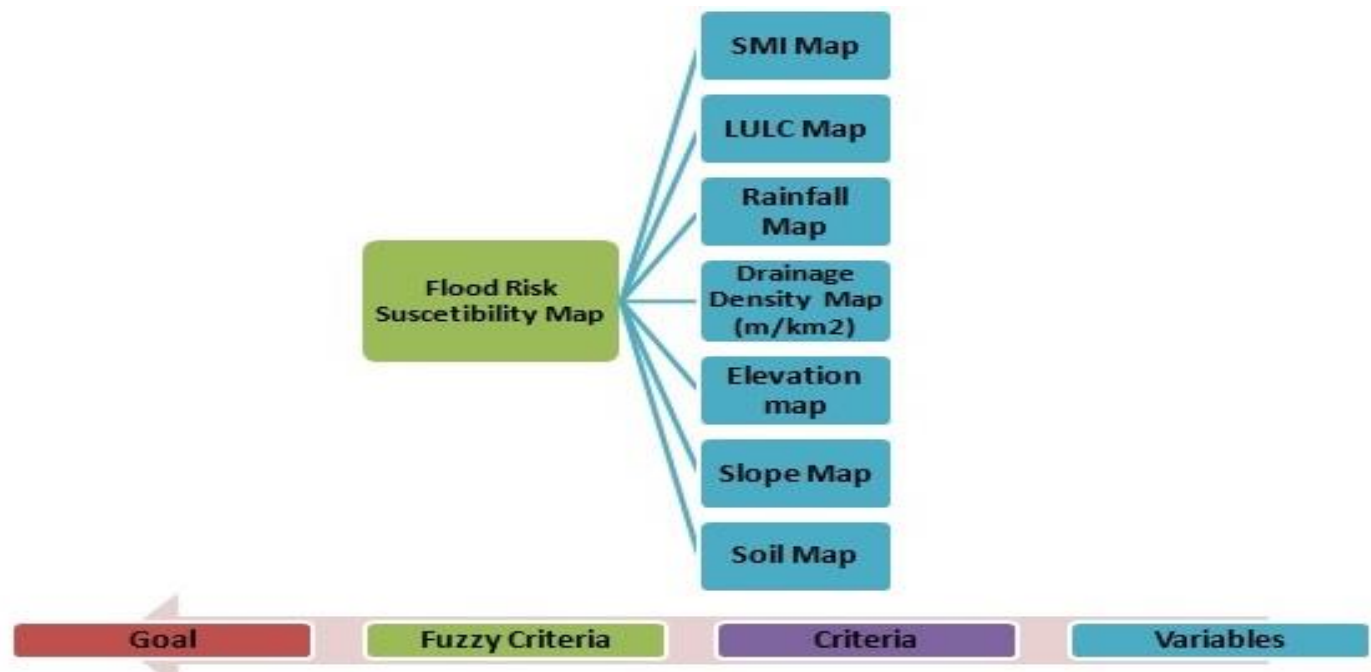

Figure 3. FAHP Analysis Workflow for Flash Flood Susceptibility Analysis.

\subsection{Methodology}

The process of identifying the flash flood susceptibility areas need to Divided into different steps (Figure 3) the first step involves preparing the flood conditioning factors (Figure 2) (Darabi et al. 2019) by using GIS technicality and geographic data; but the second step has to deal with calculating the percentage of certain Criteria Weights by using the Analytical Hierarchy Process algorithms (Echogdali et al. 2018; Saaty 1989). Furthermore, the third step includes a transformation process of the flood conditioning factors from 0 to 1 scale by using the Fuzzy Membership (linear functions) algorithm (Ait Kacem et al. 2019; Zadeh 1978). In addition, the fourth step includes the multiplication of Fuzzy Criteria with the AHP Criteria. Finally, a flash flood susceptibility map has been produced (Figure 4).

2.4.1 Analytical Hierarchy Process (AHP): The analytic hierarchy process (AHP) is a structured technique which was developed by Thomas L. Saaty. It is the most widely used for organizing, solving and analysing the complex problems. Additionally, AHP technique help to calculate weights of criteria and the relative importance of these criteria (Ait Kacem et al. 2019; Rahmati, Zeinivand, and Besharat 2016; Saaty 1989). Moreover, to check the weights of criteria value are correct or not, the Consistency ratio (CR) should be calculated, that must be less than 0 and 1 to confirm that the matrix is a reasonable consistency. This Consistency ratio (CR), is calculated using this equation (equation 3 ).

Where:

the maximum eigenvalue $(\lambda \max )$ is getting by this equation (equation 1) ; the Consistency Index (CI) getting by this equation (equation 2); And the Random Index (RI) getting according to the Random Index Table which based on the number of criteria (Echogdali et al. 2018; Elkhrachy 2015; Papaioannou et al. 2015; Rahmati et al. 2016; Saaty 1989)

$$
\text { (1) } \gamma_{\max }=\text { Average }(w s / w c)
$$

Where, $\lambda \max$ is the maximum eigenvalue.

(2) $C I=\left(\gamma_{\max }-n\right) /(n-1)$

Where, $\mathrm{n}$ is the number of criteria.

$$
\text { (3) } \mathrm{CR}=\mathrm{CI} / \mathrm{RI}
$$

2.4.2 Fuzzy Logic: Fuzzy logic is a multi-valued logic where the truth values of variables instead of being true or false are really between 0 and 1 (Ait Kacem et al. 2019). In this sense, it extends the Boolean logic classic with partial truth values 1 (Papaioannou et al. 2015). It consists of taking into account various numerical factors to arrive at a decision that one wishes to accept, and formalized by Lotfi Zadeh in 1965 (Zadeh 1978). In this case using the fuzzification algorithm in the ArcGIS environment help to transforms each flash flood raster factors into a 0 to 1 scale.

2.4.3 Fuzzy analytical hierarchy process (FAHP): (Darabi et al. 2019; Gigović et al. 2017; Papaioannou et al. 2015; Yang et al. 2013; Zadeh 1978) After calculating factor weights for each criteria (Table 3), and the fuzzification of each flash flood factor, it must be multiplied by the fuzzy logic output with AHP weight output using this equation (equation 4) then it should be combined by fuzzy overlay tool, to get finally the flash flood susceptibility map of Guelmim region (Figure 4).

(1) $\operatorname{Model}_{\mathrm{FAHP}}=\sum_{\mathrm{ni}}^{\mathrm{n}} \mathrm{W}_{\mathrm{i}} \times \mathrm{F}_{\mathrm{i}}$ 
Where:

$$
\begin{aligned}
& \mathrm{Wi}=\text { Weight of each flash flood factor. } \\
& \mathrm{Fi} \text { = Fuzzy map of each flash flood. }
\end{aligned}
$$

In this study case the FAHP calculation is:

$$
\begin{aligned}
& \text { Model }_{\mathrm{FAHP}}=[0,3700 *(\text { Fuzzy SMI })+0,2430 *(\text { Fuzzy } \\
& \text { Rainfall })+0,1557 *(\text { Fuzzy Drainage density })+0,0998 *(\text { Fuzzy } \\
& \text { LULC })+0,0639 *(\text { Fuzzy DEM })+0,0406 *(\text { Fuzzy Slope })+ \\
& 0,0270 *(\text { Fuzzy Soil })] .
\end{aligned}
$$

\section{RESULTS AND DISCUSSION}

Flash flood susceptibility maps (Figure 3) were created using the effective factors (thematic maps, Figure 2) in flood susceptibility and the FAHP (Fuzzification and Criteria Weights (\%)) algorithms.

\subsection{Variable Classification of Thematic Map}

The categorization of each flash flood factors (variable) is depending on the degree of impact a factor has on susceptibility. for example, drainage density and Rainfall have an important effect on flash flood susceptibility, therefore lower drainage density and lower rainfall regions are designated classes 1 and 2, whereas higher drainage density and higher rainfall regions are categorized 4 and 5 meaning that they are highly vulnerable to flash flood (Domeneghetti et al. 2019; Mohamed and El-Raey 2019) (Figure 2). likewise, Soil moisture index is the most important factor. Regions with less soil moisture index have minus moisture saturation ability and thus are more susceptible to flash flood. Though, regions with high soil moisture index have greater moisture saturation ability and low susceptible to flash flood (Bannari et al. n.d.; Silvestro et al. 2019). So, in the categorization phase, less soil moisture regions were marked classes 4 and 5, and great soil moisture regions were categorized as 1 and 2 (Figure 2). On the other hand regions with greater slope and altitude are marked classes 1 and 2, and regions with less slope and altitude are categorized as 4 and 5 (Figure 2), because when the rainfall occurs and with high intensity during a short period of time, the water goes under briskly in very inclined way and in the flat regions. In addition, regions with less steep and flat areas, the water goes sluggishly, this can consequently cause flash flooding (Bannari et al. 2016; Falah et al. 2019; Fenton 2019).

\subsection{Fuzzification \& Criteria Weights (\%)}

The AHP results indicated that $37 \%$ of susceptibility the flash flood is induced by Soil moisture index, $24.30 \%$ by Rainfall and 15,75 by Drainage density, therefore, is just $9,98 \%, 6,39,4,06$ and 2,70 which is induced respectively by LULC, DEM, Slope, and Soil. This result is faithful with the prior researches (Echogdali et al. 2018; Lyu et al. 2018; Rahmati et al. 2016).

\subsection{Flash Flood Susceptibility Maps}

The resulting map showed that residential areas at the outlet (red region in the North West, Figure4) of the watershed and which are close (around the rivers, Figure4) of the main effluents Sayed and Oum Laachar wadis were very susceptible to flooding and were classified in the high flash flood susceptibility class. this result is consistent with the studies (Echogdali et al. 2018; Elkhrachy 2015; Papaioannou et al. 2015).

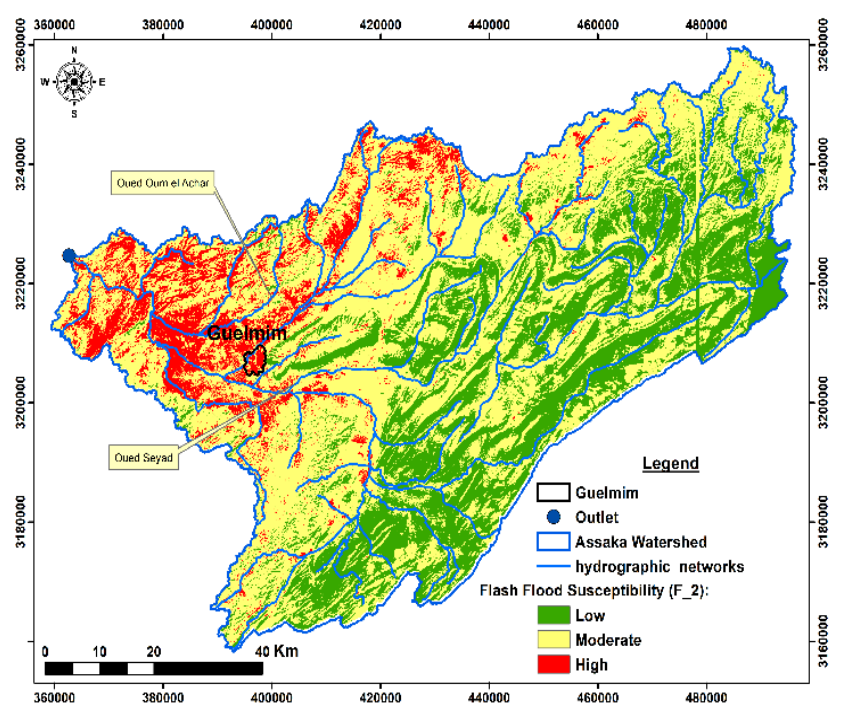

Figure 4. The flash flood susceptibility map

These flash flood susceptibility maps could use to reduce the future harm made by flash floods, to help the disaster management processes in the future, to improve greater methods for the preservation, to extend the research, to develop flash flood predictions and precaution systems. There are two flash flood susceptibility maps have been created in this study. The first map (Figure4) was created by Rainfall of November (before and during flash flood of 2014) and SMI of November 7th, 2014 (before flash flood), but the second map (Figure 4) was used Rainfall of December (after flash flood of 2014) and SMI of December 9th, 2014 (after flash flood). Remarking that the second map predicted more the flash flood susceptibility areas than the first one. Thus concluded that SMI has a very important effect in this study, which conforms to this preliminary study (Bannari et al. n.d.; Papaioannou et al. 2015; Silvestro et al. 2019).

In the resulting Flash flood susceptibility maps, the high susceptibility class covering $42,57 \%$, moderate susceptibility class covering $35,92 \%$ and the low susceptibility class covering $21,51 \%$ area of the watershed area (Figure 5).

According to HCP statistical data (2014) reveals that about $42,34 \%$ population residing in 7 common susceptible to low, 


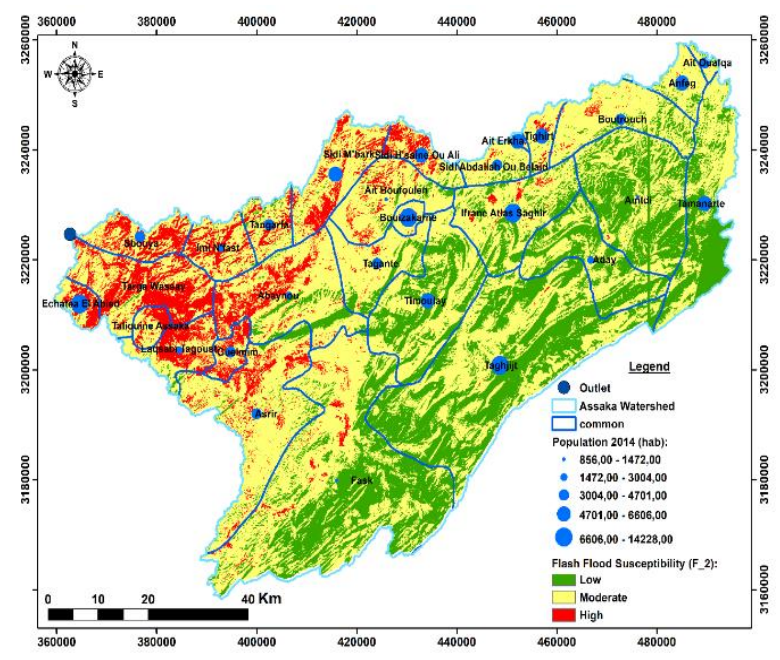

Figure 5. The residential population in a flash flood Susceptibility areas

$32,49 \%$ population belongs to 9 common susceptible to moderate and about $25,17 \%$ population part of 9 commons are Generally the FAHP approach has been used in several studies such as getting the Low-Cost Solution for Assessment of Urban Flash Flood Impacts in Ras Ghareb City, Egypt (Mohammed Sadek.2019), another study was used to get the flood hazard index in Mombasa County, Kenya (Yves Hategekimana.2018). However, the quality of the results of those preliminary studies has made the FAHP method a suitable approach for flash flood prediction in the Guelmin region.

\section{CONCLUSION}

This study combined two algorithms Fuzzy and AHP, to create a flash flood susceptibility maps by using the flash flood conditioning factors which has indicated that soil moister index, Rainfall, drainage density, altitude, slope degree, and soil type from watershed were the most influential factors in flash flood susceptibility mapping. The study totally shows the important role of GIS in the decision making-process. The produced maps in the current study indicated that a residential area at the outlet of the Assaka watershed are vulnerable to flooding and must be a preference for management to stop alleviates flash flooding. This research could be used to other zones to help managing, manipulating, and lowering of the flash flood harm in regions vulnerable to flooding.

\section{ACKNOWLEDGMENT}

At the end of this research, I would like to thank my dear professors Rhinane Hassan and Mehdi Maanan for their guidance and support throughout the realization of this study.

\section{REFERENCES}

Abdelkareem, Mohamed. 2017. “Targeting Flash Flood Potential Areas Using Remotely Sensed Data and GIS Techniques." Natural Hazards 85(1):19-37.

Ait Kacem, Hicham, Said Fal, Karim Mounir, Hicham Mharzi Alaoui, Hassan Rhinane,

and Mehdi Maanan. 2019. "Application of Fuzzy Analytical Hierarchy Process for Assessment of Desertification Sensitive Areas in North West of Morocco." Geocarto International 6049:1-18.

Bannari, A., Kadhem, G., El-Battay, A., Hameed, N.A. and Rouai, M. (2017) Detection of Areas Associated with Flash Floods and Erosion Caused by Rainfall Storm Using Topographic Attributes, Hydrologic Indices, and GIS. Chapter 13 in: Global Changes and Natural Disaster Management: Geo-information Technologies. Pirasteh, S. and Li, J. (Editors), Springer International Publishing, Germany, 209 p. DOI-10.1007/978-3-319-51844-2.

Bannari, A., G. Kadhem, A. El-Battay, N. A. Hameid, and M. Rouai. 2016. "Assessment of Land Erosion and Sediment Accumulation Caused by Runoff after a Flash-Flooding Storm Using Topographic Profiles and Spectral Indices." Advances in Remote Sensing 05(04):315-54.

Bannari, A., H. Rhinane, and H. Bahi. n.d. "Soil Moisture Mapping before , during, and after Flash-Flood Storm in Southwestern Morocco Using SMOS-MIRAS and Landsat OLI / TIRS Data."

Bisht, Sapna, Smita Chaudhry, Subrat Sharma, and Sandeep Soni. 2018. "Assessment of Flash Flood Vulnerability Zonation through Geospatial Technique in High Altitude Himalayan Watershed, Himachal Pradesh India.” Remote Sensing Applications: Society and Environment 12:3547.

Boutaleb, Said, Echogdali FZ, Jauregui J, and Elmouden A. 2018. "Cartography of Flooding Hazard in Semi-Arid Climate: The Case of Tata Valley (South-East of Morocco)." Journal of Geography \& Natural Disasters 08(01).

Carpenter, T. M., J. A. Sperfslage, K. P. Georgakakos, T. Sweeney, and D. L. Fread. 1999. "National Threshold Runoff Estimation Utilizing GIS in Support of Operational Flash Flood Warning Systems.” Journal of Hydrology 224(1-2):21-44. 
Chen, Jian, Arleen A. Hill, and Lensyl D. Urbano. 2009. "A GIS-Based Model for Urban Flood Inundation.” Journal of Hydrology 373(1-2):184-92.

Curebal, Isa, Recep Efe, Hasan Ozdemir, Abdullah Soykan, and Süleyman Sönmez. 2016. "GIS-Based Approach for Flood Analysis: Case Study of Keçidere Flash Flood Event (Turkey)." Geocarto International 31(4):355-66.

Darabi, Hamid, Bahram Choubin, Omid Rahmati, Ali Torabi Haghighi, Biswajeet Pradhan, and Bjørn Kløve. 2019. "Urban Flood Risk Mapping Using the GARP and QUEST Models: A Comparative Study of Machine Learning Techniques.” Journal of Hydrology 569:14254.

Dawod, Gomaa M., Meraj N. Mirza, and Khalid A. Al-Ghamdi. 2011. "GIS-Based Spatial Mapping of Flash Flood Hazard in Makkah City, Saudi Arabia." Journal of Geographic Information System 03(03):225-31.

Domeneghetti, Alessio, Guy J. P. Schumann, and Angelica Tarpanelli. 2019. "Preface: Remote Sensing for Flood Mapping and Monitoring of Flood Dynamics." Remote Sensing 11(8):943.

Echogdali, Fatima Zahra, Said Boutaleb, Ahmed Elmouden, and Mohammed Ouchchen. 2018. “Assessing Flood Hazard at River Basin Scale: Comparison between HECRASWMS and Flood Hazard Index (FHI) Methods Applied to El Maleh Basin, Morocco.” Journal of Water Resource and Protection 10(09):957-77.

Elkhrachy, Ismail. 2015. "Flash Flood Hazard Mapping Using Satellite Images and GIS Tools: A Case Study of Najran City, Kingdom of Saudi Arabia (KSA).” Egyptian Journal of Remote Sensing and Space Science 18(2):261-78.

Falah, Fatemeh, Omid Rahmati, Mohammad Rostami, Ebrahim Ahmadisharaf, Ioannis N. Daliakopoulos, and Hamid Reza Pourghasemi. 2019. Artificial Neural Networks for Flood Susceptibility Mapping in Data-Scarce Urban Areas. Elsevier Inc.

Fenton, John D. 2019. "Flood Routing Methods." Journal of Hydrology 570(January):251-64.

Gigović, Ljubomir, Dragan Pamučar, Zoran Bajić, and Siniša Drobnjak. 2017. “Application of GIS-Interval Rough AHP Methodology for Flood Hazard Mapping in Urban Areas." Water (Switzerland) 9(6):1-26.

Hakdaoui, Sofia, Anas Emran, Biswajeet Pradhan, Chang Wook Lee, and Salomon Cesar Nguemhe Fils. 2019. "A Collaborative Change Detection Approach on Multi-
Sensor Spatial Imagery for Desertwetland Monitoring after a Flash Flood in Southern Morocco." Remote Sensing 11(9).

Hallegatte, Stéphane, Jean Charles Hourcade, and Patrice Dumas. 2007. "Why Economic Dynamics Matter in Assessing Climate Change Damages: Illustration on Extreme Events.” Ecological Economics 62(2):330-40.

Hategekimana, Yves, Lijun Yu, Yueping Nie, Jianfeng Zhu, Fang Liu, and Fei Guo. 2018. "Integration of MultiParametric Fuzzy Analytic Hierarchy Process and GIS along the UNESCO World Heritage: A Flood Hazard Index, Mombasa County, Kenya." Natural Hazards 92(2):1137-53.

Hoegh-Guldberg, Ove and John F. Bruno. 2010. “The Impact of Climate Change On.” Science 328(June):1523-29.

Jongman, B., H. Kreibich, H. Apel, J. I. Barredo, P. D. Bates, L. Feyen, A. Gericke, J. Neal, J. C. J. H. Aerts, and P. J. Ward. 2012. "Comparative Flood Damage Model Assessment: Towards a European Approach." Natural Hazards and Earth System Science 12(12):3733-52.

Jonkman, S. N., M. Bočkarjova, M. Kok, and P. Bernardini. 2008. "Integrated Hydrodynamic and Economic Modelling of Flood Damage in the Netherlands." Ecological Economics 66(1):77-90.

El Khalki, El Mahdi, Yves Tramblay, Mohamed El Mehdi Saidi, Christophe Bouvier, Lahoucine Hanich, Mounia Benrhanem, and Meriem Alaouri. 2018. "Comparison of Modeling Approaches for Flood Forecasting in the High Atlas Mountains of Morocco." Arabian Journal of Geosciences 11(15).

Lyu, Hai Min, Wen Juan Sun, Shui Long Shen, and Arul Arulrajah. 2018. "Flood Risk Assessment in Metro Systems of Mega-Cities Using a GIS-Based Modeling Approach.” Science of the Total Environment 626:101225 .

Mashaly, Jehan and Eman Ghoneim. 2018. "Flash Flood Hazard Using Optical, Radar, and Stereo-Pair Derived DEM: Eastern Desert, Egypt.” Remote Sensing 10(8):1204.

Mohamed, Soha A. and Mohamed E. El-Raey. 2019. "Vulnerability Assessment for Flash Floods Using GIS Spatial Modeling and Remotely Sensed Data in El-Arish City, North Sinai, Egypt." Natural Hazards (0123456789).

Motevalli, Alireza and Mehdi Vafakhah. 2016. "Flood Hazard Mapping Using Synthesis Hydraulic and Geomorphic 
Properties at Watershed Scale.” Stochastic Environmental Research and Risk Assessment 30(7):1889-1900.

O’Mara, Kaitlyn, Jon M. Olley, Brian Fry, and Michele Burford. 2019. "Catchment Soils Supply Ammonium to the Coastal Zone - Flood Impacts on Nutrient Flux in Estuaries." Science of the Total Environment 654:58392.

Papaioannou, G., L. Vasiliades, and A. Loukas. 2015. "MultiCriteria Analysis Framework for Potential Flood Prone Areas Mapping." Water Resources Management 29(2):399-418.

Rahmati, Omid, Hossein Zeinivand, and Mosa Besharat. 2016. "Flood Hazard Zoning in Yasooj Region, Iran, Using GIS and Multi-Criteria Decision Analysis." Geomatics, Natural Hazards and Risk 7(3):1000-1017.

Ryu, Kee Young, Jae Hoon Cho, Sung Lak Lee, Dong Gee Kang, and Sang Chul Kim. 1997. “요추간수핵탈출증에서 경피적 내시경 수핵절제술과 미세현미경 수술의 비교 분석 Preliminary Results.” 26:946-52.

Saaty, Thomas L. 1989. "Group Decision Making and the AHP.” The Analytic Hierarchy Process 59-67.

Schulz, O., H. Busche, and A. Benbouziane. 2008. "Decadal Precipitation Variances and Reservoir Inflow in the SemiArid Upper Drâa Basin (South- Eastern Morocco)." Climatic Changes and Water Resources in the Middle East and North Africa 165-78.

Silvestro, F., L. Rossi, L. Campo, A. Parodi, E. Fiori, R. Rudari, and L. Ferraris. 2019. "Impact-Based Flash-Flood Forecasting System: Sensitivity to High Resolution Numerical Weather Prediction Systems and Soil Moisture.” Journal of Hydrology 572:388-402.

TARGA-AIDE and Zurich Insurance. 2014. "Risk Nexus Morocco Floods of 2014: What We Can Learn from Guelmim and Sidi Ifni." 30.

Tazik, Esmaeil, Zahra Jahantab, Mohsen Bakhtiari, Abdolali Rezaei, and Seyed Kazem Alavipanah. 2014. "Landslide Susceptibility Mapping by Combining the Three Methods Fuzzy Logic, Frequency Ratio and Analytical Hierarchy Process in Dozain Basin.” International Archives of the Photogrammetry, Remote Sensing and Spatial Information Sciences - ISPRS Archives 40(2W3):26772.
Theilen-Willige, Barbara, Abdessamad Charif, Abdelhadi Ouahidi, Mohamed Chaibi, Mohamed Ougougdal, and Halima AitMalek. 2015. "Flash Floods in the Guelmim Area/Southwest Morocco-Use of Remote Sensing and GIS-Tools for the Detection of Flooding-Prone Areas.” Geosciences 5(2):203-21.

Tramblay, Y., R. Bouaicha, L. Brocca, W. Dorigo, C. Bouvier, S. Camici, and E. Servat. 2012. "Estimation of Antecedent Wetness Conditions for Flood Modelling in Northern Morocco." Hydrology and Earth System Sciences 16(11):4375-86.

Wang, Weicai, Xiaoxin Yang, and Tandong Yao. 2012. "Evaluation of ASTER GDEM and SRTM and Their Suitability in Hydraulic Modelling of a Glacial Lake Outburst Flood in Southeast Tibet." Hydrological Processes 26(2):213-25.

Werren, Gabriela, Emmanuel Reynard, Stuart N. Lane, and Daniela Balin. 2016. "Flood Hazard Assessment and Mapping in Semi-Arid Piedmont Areas: A Case Study in Beni Mellal, Morocco.” Natural Hazards 81(1):481-511.

Yang, Chia Lee, Ming Chang Shieh, Chi Yo Huang, and Ching Pin Tung. 2018. “A Derivation of Factors Influencing the Successful Integration of Corporate Volunteers into Public Flood Disaster Inquiry and Notification Systems.” Sustainability (Switzerland) 10(6).

Yang, Xiao ling, Jie hua Ding, and Hui Hou. 2013. “Application of a Triangular Fuzzy AHP Approach for Flood Risk Evaluation and Response Measures Analysis.” Natural Hazards 68(2):657-74.

Zadeh, L. A. 1978. "F u z z y s e t s as a Basis for a Theory of Possibility* 1.a. z a d e H.” Division, Computer Science Sciences, Computer 1:3-28. 